\title{
Electrical Resistivity and NTC/PTC Transition Point of a Nitrogen-Doped SiC Igniter, and Their Correlation to Electrical Heating Properties
}

\author{
Young-Sam Jeon, Hyunho Shin*,٪, Dong-Joo Yoo, and Sang-Ok Yoon* \\ Immersing Laboratory, LG Electronics Institute of Technology, Seoul 137-724, Korea \\ *Department of Advanced Ceramic Materials Engineering, Gangneung-Wonju National University, Gangneung 210-702, Korea
}

(Received November 28, 2011; Revised January 2, 2012; Accepted January 5, 2012)

\begin{abstract}
An M-shaped SiC gas igniter was fabricated by a reaction sintering followed by nitrogen doping. The igniter showed both resistivity at room temperature and NTC to PTC transition temperature values that were lower than those of commercial igniters. It was deduced that the doped nitrogen reduces the electrical resistivity at room temperature, while, at high temperature, the doped nitrogen and a trace of $\mathrm{Si}_{3} \mathrm{~N}_{4}$ phase work as scattering centers against electron transfer, resulting in a lowered NTC-to-PTC transition point (below $650^{\circ} \mathrm{C}$ ). Such characteristics were correlated to the fast heating speed (as compared to the commercial models) and to the prevention of the high temperature overshooting of the nitrogen-doped $\mathrm{SiC}$ igniter.
\end{abstract}

Key words : Reaction sintered SiC, Nitrogen doping, Electrical heating, NTC, PTC

\section{Introduction}

$\mathrm{H}$ eaters used for hot-surface gas igniters require fast rising temperature, prevention of high temperature overshooting, and good high temperature stability. Semiconducting silicon carbide has been predominantly used in hot-surface gas igniters because its negative temperature coefficient (NTC) of resistivity ${ }^{1)}$ results in an initial fast rising temperature, while its transition to positive temperature coefficient (PTC) of resistivity at moderately high temperature (e.g., about $\left.800^{\circ} \mathrm{C}\right)^{1)}$ prevents an overly high current input to limit high-temperature overshooting. It is further well known that the silica scale on $\mathrm{SiC}$ surfaces provides protection against high temperature oxidation of $\mathrm{SiC}^{2)}$

According to our unpublished study based on microstructure and various characterizations, existing commercial SiC heaters are believed to be fabricated by recrystallization (Norton Inc.) or reaction sintering (Surface Igniter Co., SIC). Reaction sintering is the lowest-cost $\mathrm{SiC}$ fabrication process among other routes, and is a promising method to fabricate $\mathrm{SiC}$ heaters. In addition to applications to gas igniters, reaction sintered SiCs (RSSCs) have received considerable interest for applications to various compartments in semiconductor processing, nuclear fuel preparation, and high temperature thermomechanical applications. $^{3,4)}$

RSSCs are usually fabricated by infiltrating silicon melt into a porous SiC-C preform. ${ }^{5-8)}$ A drawback of RSSCs for SiC heater applications would be the fact that a considerable amount

${ }^{\dagger}$ Corresponding author: Hyunho Shin

E-mail : hshin@gwnu.ac.kr

Tel : +82-33-640-2484 Fax : +82-33-640-2244 of residual silicon exists after reaction sintering, which works as a source to degrade the high temperature stability and to screen the electrical NTC/PTC behavior of SiC. Recently, the current research group reported that residual silicon can be eliminated by a post process such as evaporation at temperatures higher than those of the reaction sintering. ${ }^{9,10)}$

For the initial fast rising of temperature by joule heating of a $\mathrm{SiC}$ igniter, a decreased electrical resistivity is highly important. In this regard, nitrogen doping can be a good approach. Recently, it was reported that nitrogen heat treatment of the $\mathrm{RSSC}^{9)}$ or the introduction of nitrogen sources such as hexa-methylene-tetra-amine in the preform for $\mathrm{RSSC}^{11)}$ yielded a significantly diminished electrical resistivity. More specifically, electrical resistivity of approximately $0.9 \Omega \cdot \mathrm{cm}$ was achieved as compared to a resistivity of $550 \Omega \cdot \mathrm{cm}$ in the case in which no nitrogen source was used. ${ }^{11)}$

In our previous work, ${ }^{9)}$ the in-situ formation of beta phase $\mathrm{SiC}$ during the reaction sintering of alpha $\mathrm{SiC}$ preforms was investigated based on quantitative X-ray diffraction (XRD) analysis. It was also reported that the heat-treatment of the reaction sintered $\mathrm{SiC}$ in $\mathrm{N}_{2}$ atmosphere facilitated the nitrogen doping to the in-situ forming beta $\mathrm{SiC}$ with the formation of a trace of $\mathrm{Si}_{3} \mathrm{~N}_{4}$ undetectable by XRD. ${ }^{9)}$ In this subsequent work, we report that, when an M-shaped igniter (LGK) was fabricated from such a nitrogen-doped $\mathrm{SiC}$, it demonstrates a faster rising temperature and better overshooting resistance than do the existing commercial hot-surface igniter heaters. The current work aims to correlate the electrical resistivity and the NTC/PTC transition point of the nitrogen-doped $\mathrm{SiC}$ igniter (LGK) to its electrical heating properties. 


\section{Experimental Procedure}

The detailed processing route to prepare reaction-sintered $\mathrm{SiC}$ is described in our previous work. ${ }^{9)}$ Describing the heat treatment schedule (Fig. 1), the resin-coated $\alpha$-SiC preform and silicon were heated in a vacuum furnace with a graphite heating element to $1000^{\circ} \mathrm{C}$ at $10^{\circ} \mathrm{C} / \mathrm{min}$; temperature was then held for $30 \mathrm{~min}$, and then sample was heated to $1600^{\circ} \mathrm{C}$ at $20^{\circ} \mathrm{C} / \mathrm{min}$; temperature was held for $30 \mathrm{~min}$ for reaction sintering, and sample was cooled thereafter. During reaction sintering at $1600^{\circ} \mathrm{C}$ for $30 \mathrm{~min}$, vacuum pressure varied from 100 to 30 mtorr; the cooled samples were termed the reaction sintered (RS) specimens. Some RS samples were reheated to $1700^{\circ} \mathrm{C}$ for $30 \mathrm{~min}$ in vacuum (pressure changed from 100 to 50 mtorr due to the silicon removal), followed by cooling; these samples were termed the evaporated (EV) specimens. Finally, some RS samples were reheated to $1700^{\circ} \mathrm{C}$ for $30 \mathrm{~min}$ in vacuum for silicon evaporation, followed by introduction of a flowing $10 \% \mathrm{H}_{2}-90 \% \mathrm{~N}_{2}$ at $1.02 \mathrm{MPa}$ of positive pressure for $90 \mathrm{~min}$ at the same temperature, after which the furnace was cooled; these samples were termed the nitridation (NI) specimens. The SiC igniter was fabricated by using NI material, and was named LGK.

The crystal phases of the SIC, Norton, and LGK igniters were analyzed by powder X-ray diffraction (D/MAX-2500H, Rigaku, Tokyo, Japan) with $\mathrm{Cu} \mathrm{K} \alpha$ radiation at a scan rate of $0.02 \%$ step and with a duration time of $1 \mathrm{sec}$ at each step. Since a $20 \mathrm{wt} \%$ of $\mathrm{MgO}$ was added to the LGK (NI) sample as an internal standard in the previous work ${ }^{9)}$ (to quantify the crystal phases), the same amount of internal standard was added to SIC and Norton specimens for comparison purposes in the present work; Since the three samples were analyzed with a time interval of more than a few months, the peak intensity of the internal standard $\mathrm{MgO}$ in each sample can be used as a reference to compare the peak intensities of the silicon carbide phase in each sample.

For the measurement of electrical resistivity, RS, EV, and NI specimens were cut into the shapes shown in Fig. 2(a). The LGK igniter was machined as seen in Fig. 2(b). An appropriate length of the end portions of the RS, EV, and NI specimens, were spray coated with aluminum, and the current was measured at a constant voltage ( 27 volts), from which the resistance was determined.

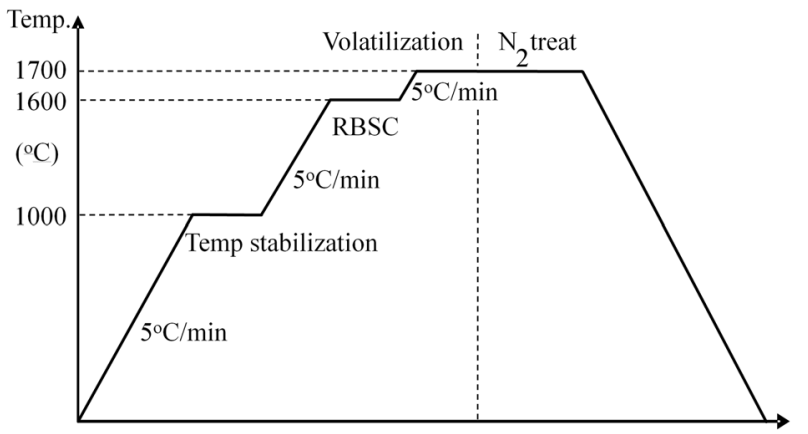

Fig. 1. Schematic illustration of the heat treatment schedule.
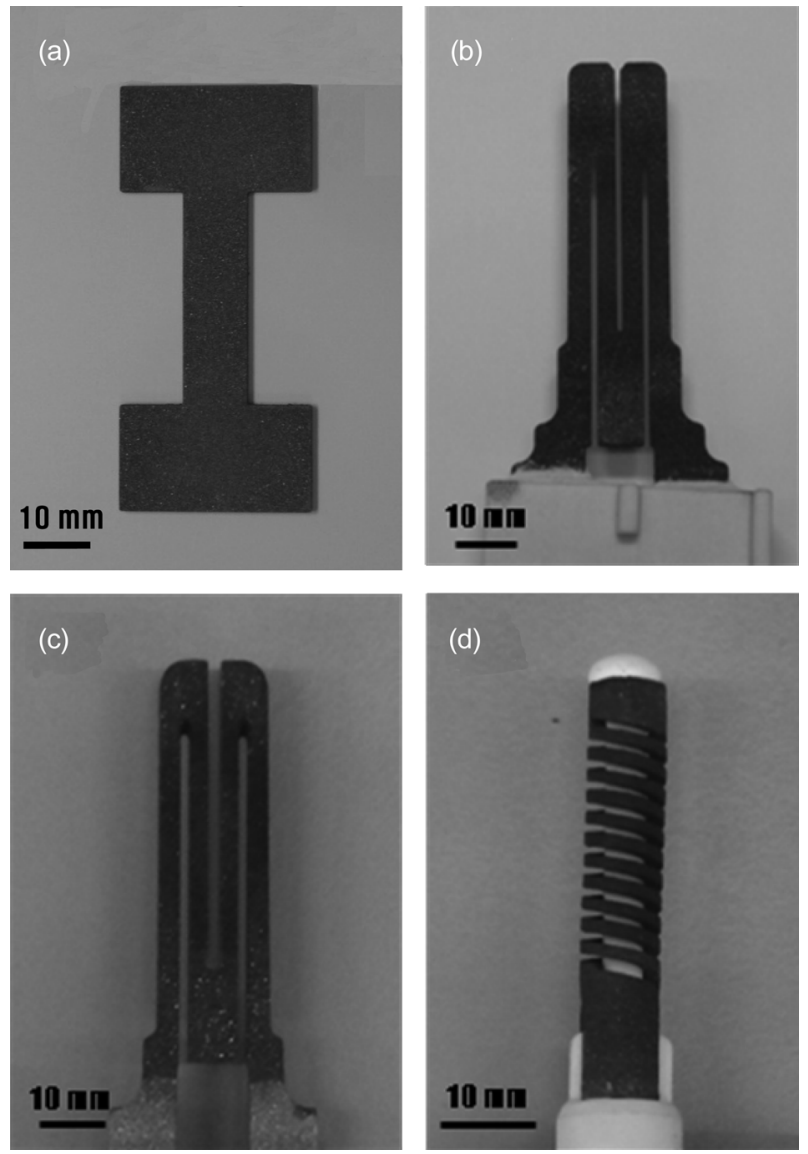

Fig. 2. Photographs for (a) NI specimen used for resistivity measurement, (b) LGK igniter fabricated from the NI material, and commercial igniters from (c) Norton Inc. and (d) Surface Igniter Co. (SIC).

Unlike the RS, EV, and NI (Fig. 2(a)) specimens, the igniters (LGK, Norton, and SIC; Fig. 2(b)-2(d)) have complicated geometry with various parts having different cross sectional areas and lengths. The room temperature resistivity of the igniters was determined from the measured resistance based on the relation,

$$
R_{\text {measured }}=\sum_{i} \rho_{R T} \frac{l_{i}}{A_{i}}
$$

where $R$ is the resistance, $\rho_{R T}$ is the room temperature resistivity, $l$ is the length, $A$ is the cross sectional area, and the subscript $i$ is the integer denoting various parts with different length and cross sectional area in the igniter.

The high temperature resistivity of the igniters was determined by the relation,

$$
R_{\text {measured }}=\sum_{i} \rho_{R T} \frac{l_{i}}{A_{i}}+\sum_{i} \rho_{H T} \frac{l_{j}}{A_{j}}
$$

where $\rho_{H T}$ is the high temperature resistivity, and the subscripts $i$ and $j$ are the integers denoting the non-heating (thick parts) and heating parts (thin parts) in the igniter, respectively. The resistivity of the RS, EV, and NI specimens was also measured 
based on Equations (1) and (2). In the process of determining the high temperature resistivity, it was assumed that the electrical resistivity of the non-heating portion (thick parts) was maintained at the same value at room temperature. The temperature rise of the heating portion during the joule heating was monitored by using an optical pyrometer.

\section{Results and Discussion}

In general, nitrogen doping into a normal $\mathrm{SiC}$ lattice seems to be unfeasible because the bulk diffusivity of nitrogen in $\mathrm{SiC}$ is very low (only $5 \times 10^{-12} \mathrm{~cm}^{2} / \mathrm{s}$ ). However, the diffusivity of nitrogen in $\mathrm{SiC}$ was reportedly improved significantly $\left(2.4 \times 10^{-5} \mathrm{~cm}^{2} / \mathrm{s}\right)$ by employing a laser implantation during the SiC lattice-forming stage. ${ }^{12)}$ As for the documented nitrogen doping phenomenon, especially during the reaction sintering of $\mathrm{SiC}{ }^{9,11)}$ it is worth addressing what was explained in our previous work. ${ }^{9)}$ Because (1) the secondary SiC ( $\beta$ phase) particles form via a solution-reprecipitation process from a carbon-dissolved silicon melt, ${ }^{13-15)}$ and (2) the solubility of nitrogen in liquid silicon is non-negligible $(0.003 \sim 0.03$ at\% at $\left.1873 \mathrm{~K}^{16)}\right)$ as compared to that of carbon $\left(0.02\right.$ at\% at $\left.1873 \mathrm{~K}^{17)}\right)$, nitrogen doping could be achieved via the presence of a nitrogendissolved liquid, from which the doped $\beta$ phase forms (the phase fractions are reported in the previous work ${ }^{9)}$ ). Thus, the hosting of nitrogen atoms in the lattice would be more suitable during the in-situ forming stage from the nitrogen-dissolved liquid as compared to the case of direct diffusion to an $\mathrm{SiC}$ lattice from nitrogen gas. ${ }^{9)}$

Fig. 3 shows the change in electrical resistivity of the specimens at different processing stages. The resistivity of the RS specimen is the lowest, due to the abundant residual silicon surrounding the primary $\mathrm{SiC}$ ( $\alpha$-phase). The evaporation (EV) process increases the electrical resistivity significantly due to the removal of the residual silicon. The EV specimen

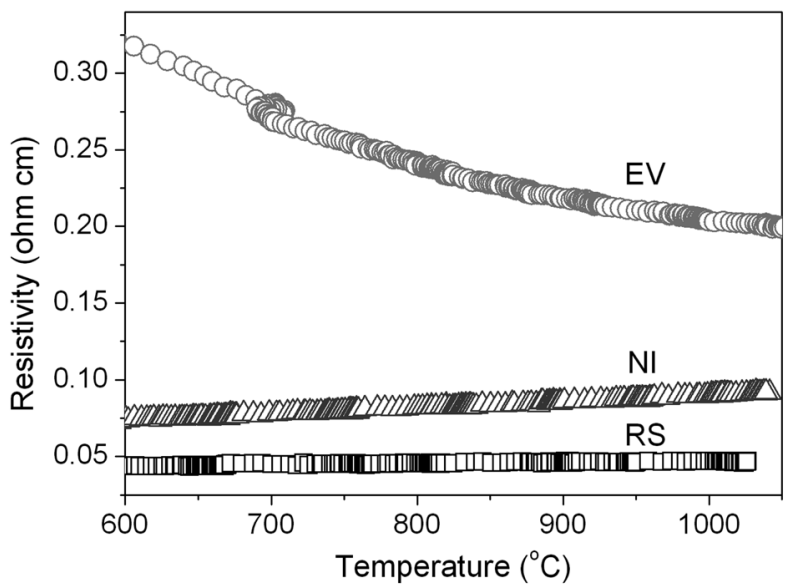

Fig. 3. Change in electrical resistivity of the specimens as a function of rising temperature during the joule heating. RS: reaction sintered specimen, EV: reaction sintered and evaporated specimen, and NI: reaction sintered, evaporated, and nitrogen-heat-treated specimen. Data adapted from Ref. shows NTC behavior. This trend is against the general trend of the primary $\mathrm{SiC}$ ( $\alpha$ phase), showing slight PTC behavior in the same temperature regime. ${ }^{1)}$ Such marked NTC behavior of the EV specimen indicates that the newly forming secondary $\beta$-SiC particles (with NTC characteristics ${ }^{1)}$ ) at the contact points of the primary $\mathrm{SiC}^{18)}$ indeed govern the electrical conduction.

As nitrogen is doped (NI specimen), the resistivity decreases $\left(0.082 \Omega \mathrm{cm}\right.$ at $\left.800^{\circ} \mathrm{C}\right)$ as compared to the $\mathrm{EV}$ specimen $\left(0.242 \Omega \mathrm{cm}\right.$ at $\left.800^{\circ} \mathrm{C}\right)$ in the investigated temperature regime. The nitrogen heat treatment also switches back to slight PTC behavior at $600 \sim 1050^{\circ} \mathrm{C}$. This phenomenon is fairly interesting because the $\beta-\mathrm{SiC}$ is known to show NTC behavior, which will be discussed later in this work.

Fig. 4 compares powder XRD patterns from NI (LGK), Norton, and SIC specimens. All the specimens turn out to be composed of $\alpha(6 \mathrm{H}$ and $15 \mathrm{R})$ and $\beta(3 \mathrm{C})$ phases, while the $6 \mathrm{H} / 15 \mathrm{R}$ ratio is lowest for Norton specimen. In reaction sintered SiC, the $\beta$ phase newly forms during reaction sintering (especially in nitrogen atmosphere ${ }^{9)}$ ) and exists at the contact points of the primary $\alpha$ phase, as mentioned. In Fig. 4, LGK and SIC specimens show similar phase fractions, possibly due to the fact that both are fabricated by reaction sintering.

An M-shaped gas igniter (LGK) was fabricated with the NI material, as can be seen in Fig. 2(b). The change in electrical resistivity of the LGK igniter during the joule heating is shown in Fig. 5(a), as a function of rising temperature. For comparison purposes, the same plot is illustrated in Fig. 5(b) and Fig. 5(c) for the commercial hot-surface igniter $\mathrm{SiC}$ from Norton Inc. and that from SIC, respectively. Note, as mentioned earlier, that the high temperature resistivity was determined by assuming that the temperature of the non-heating portion is maintained at room temperature. Thus, the absolute magnitude of the high temperature resistivity of the gas igniters, with complicated geometry based on Equation (2), does not have a high significance. Further, the fact that there is no clear boundary between the heating and non-heating portions lowers

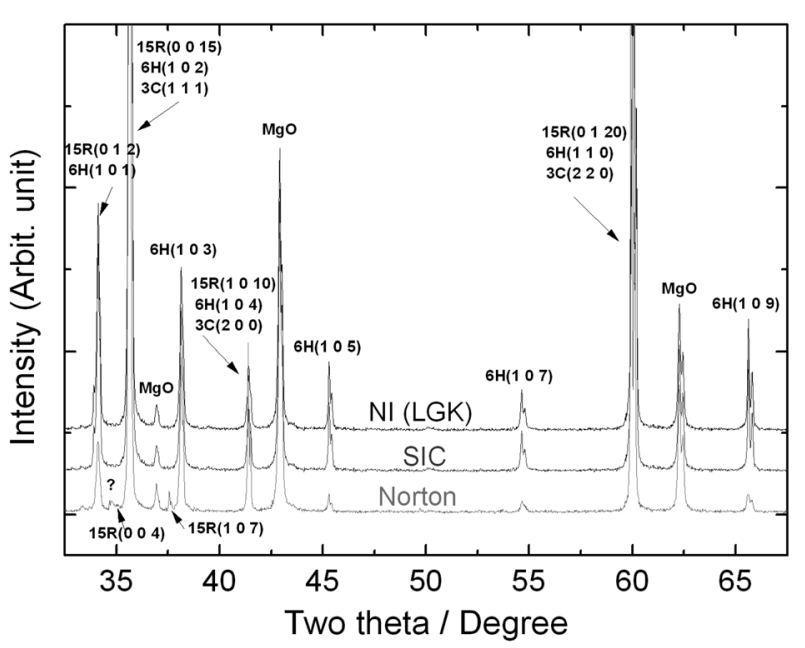

Fig. 4. Powder XRD patterns from NI (LGK), Norton, and $\mathrm{SiC}$ specimens, all of which had $20 \mathrm{wt} \% \mathrm{MgO}$ as internal standard. 

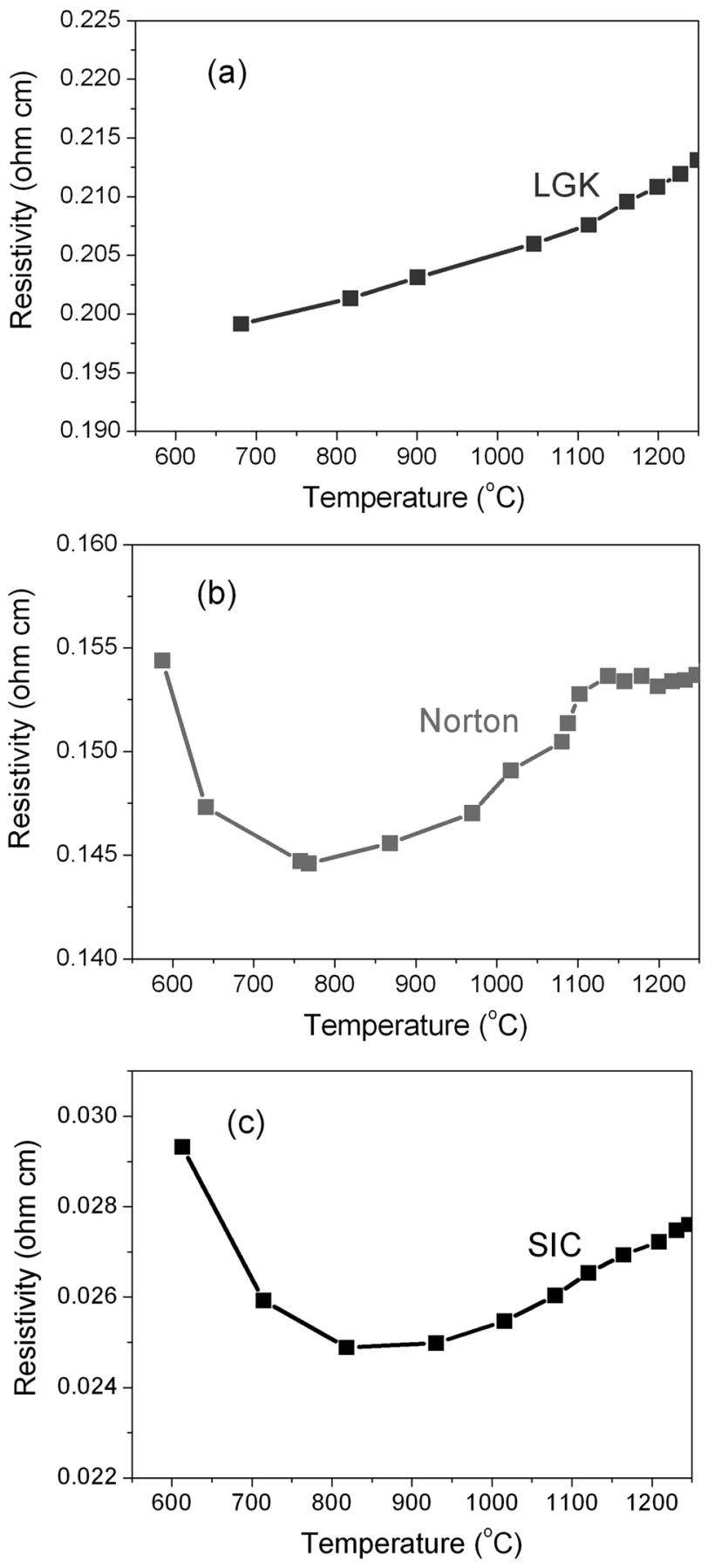

Fig. 5. Change in electrical resistivity of the igniters as a function of the temperature of the hot portion during the joule heating. (a) LGK, (b) Norton, and (c) SIC igniters. the reliability of the determined absolute value of the high temperature resistivity ${ }^{\dagger}$. However, the phenomenon of decrease or increase of the resistivity with temperature has an important physical meaning as the indicator of the negative temperature coefficient (NTC) or positive temperature coefficient (PTC).

It can be seen in Fig. 5 that the NTC characteristics change to PTC characteristics at about 770 and $850^{\circ} \mathrm{C}$ for the igniters of Norton Inc. and SIC, respectively. However, the LGK igniter exhibits a simple PTC behavior from $650^{\circ} \mathrm{C}$, from which the temperature measurement of the specimen surface was possible with an optical pyrometer. This means that the NTC to PTC transition point is at least less than or equal to $650^{\circ} \mathrm{C}$ for the LGK specimen. This view is based on the well-documented fact that both $\alpha$ and $\beta$ phases show NTC behavior at low temperature, while the $\alpha$ phase transits to PTC behavior at high temperature, ${ }^{1)}$ possibly due to the thermal vibration of the lattice.

A plausible reason why the N-doped RSSC in the current work (NI in Fig. 3 and LGK in Fig. 5) shows a lowered NTC/PTC transition point (as compared to that of commercial models) is as follows. It is deduced that the doped nitrogen works as a scattering center against electron transfer in the investigated temperature regime. Further, it has been reported ${ }^{9)}$ that the heat treatment of the RSSC in nitrogen atmosphere forms a trace of $\mathrm{Si}_{3} \mathrm{~N}_{4}$ insulating phase (another scattering center against electrical conduction); therefore, as the thermal vibration of the scattering centers (i.e., an obstacle to electrical conduction) is becoming more dominant with temperature, the PTC behavior appears at a lower temperature (below $650^{\circ} \mathrm{C}$ ) as compared to the case of the existing igniters based on undoped SiC. Therefore, only PTC behavior is observed above $650^{\circ} \mathrm{C}$ (Figs. 3 and $5(\mathrm{a})$ ).

The change in electrical resistivity as a function of joule heating time is shown in Fig. 6. The LGK hot-surface igniter demonstrates the lowest resistivity at room temperature (at time of zero), which is ascribed to the nitrogen doping. An important point in Fig. 6 is that the LGK igniter demonstrates the smallest drop of resistivity from the value at time of zero (at room temperature) to the value at longer heating time, e.g., 25 50 sec (at high temperature), yielding the most high resistivity at high temperature. The SIC igniter shows the most significant resistivity drop with heating time. A small resistivity drop for an igniter is very important in a hot-surface gas igniter in order to prevent an overly high current input to the igniter at higher temperature, i.e., the high temperature overshooting phenomenon. The smallest resistivity drop of the LGK igniter results from the lowest NTC to PTC transition point (Fig. 5), which, in turn, can be ascribed to the presence

\footnotetext{
'The high temperature resistivity, determined based on Equation (2) for the RS, EV, and NI specimens (Fig. 3), is more reliable than the igniters (LGK, Norton, and SIC; Fig. 4), because the RS, EV, and NI specimens have simpler geometry (Fig. 2(a)) than that of the igniters (Figs. 2(b)-2(d)). Unlike the high temperature value, the room temperature resistivity of the RS, EV, and NI specimens shown in Fig. 3 based on Equation (1) is relatively reliable. For the case of the room temperature resistivity of the Norton igniter, there were some uncertainties in the measurement of the cross sectional area due to the cutting saw indent. For the SIC igniter, there were uncertainties in measuring the dimensions of the non-heating cylinder portion due to the connection of the helical heating portion.
} 


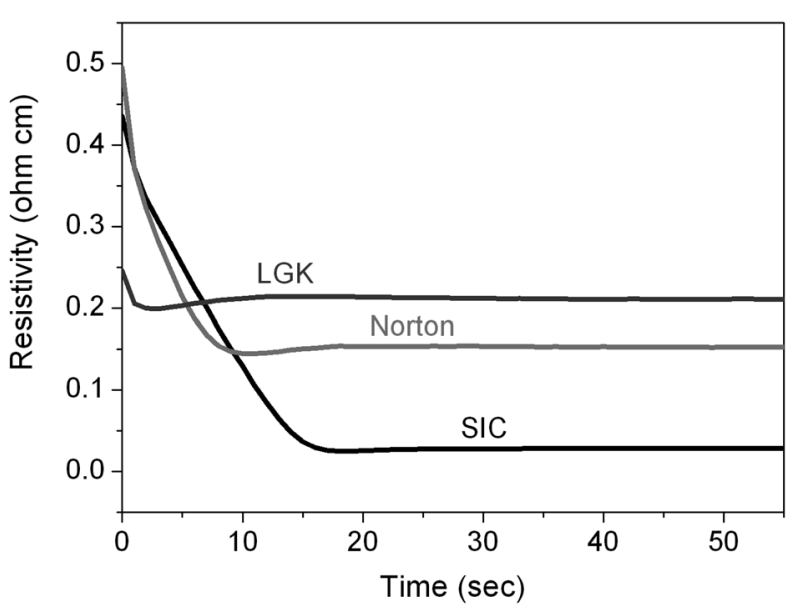

Fig. 6. Change in electrical resistivity of the igniters as a function of joule heating time.

of a thermal scattering center, such as a trace of $\mathrm{Si}_{3} \mathrm{~N}_{4}$.

In order to prevent high temperature overshooting, the total resistance of the SIC igniter having the most significant resistivity drop needs to be designed to have a higher value than that of other igniters by adjusting the total length and the cross sectional areas of the igniter; the situation would be vice versa for the LGK igniter with the smallest resistivity drop. When the room temperature resistance of the igniters was measured, indeed it was the case: 380,85 , and $45 \Omega$ for the, SIC, Norton, and LGK igniters, respectively. The LGK with the smallest resistivity drop (the highest resistivity at high temperature; Fig. 6) allowed the design of the LGK igniter to have the lowest total resistance ( $45 \Omega$ ). The reduced total resistance of the LGK igniter will increase the heating speed. On the other hand, the prevention of the high temperature overshooting phenomenon of the LGK igniter needs to be checked, although it demonstrated the highest resistivity at high temperature due to the smallest resistivity drop (Fig. 6).

Fig. 7 compares the temperature rise of the igniters as a function of time. Power input was started at the time of zero in the abscissa. A notable difference exists in heating speed, including the incubation time, due to the difference in total resistance of the igniters. The Norton igniter, because its resistance $(85 \Omega)$ is smaller than that of the SIC (380 $\Omega$ ) igniter, demonstrates faster heating. The LGK, which has the lowest total resistance ( $45 \Omega$ ), demonstrates the fastest heating speed (including incubation time), as was anticipated.

Interestingly, not only the Norton and SIC igniters with their higher resistivity ( 85 and $380 \Omega$, respectively), but also the LGK igniter, which has the lowest total resistivity (45 $\Omega$ ), successfully prevent high temperature overshooting. This finding means that the LGK igniter, which has the smallest resistivity drop to yield the highest resistivity at high temperature (Fig. 6), indeed functions efficiently at high temperature.

By exploiting the superior material characteristics of the LGK igniter, as shown in Figs. 5, 6, i.e., (1) the lowest room temperature resistivity, due to the nitrogen doping, and (2) the

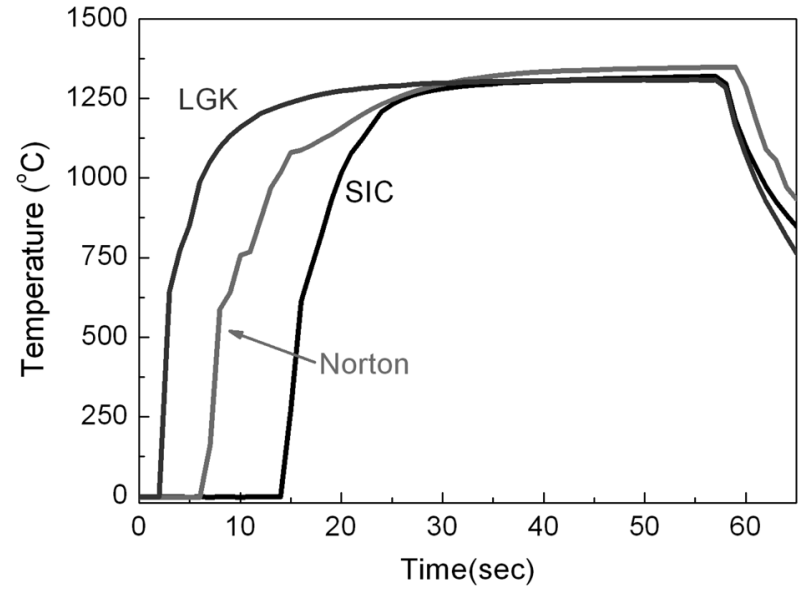

Fig. 7. Change in temperature of the hot portion of the igniters as a function of joule heating time.

smallest resistivity drop with heating (the highest resistivity at high temperature) due to the lowered NTC to PTC transition point (which, in turn, can be ascribed to the presence of a thermal scattering center such as a trace of $\mathrm{Si}_{3} \mathrm{~N}_{4}$ ), the LGK igniter could be designed to have a resistance as low as $45 \Omega$. An N-doped SiC-based LGK igniter with such characteristics demonstrates a fast heating speed while it efficiently prevents high temperature overshooting (Fig. 7). This finding means that the process reported in the existing work, ${ }^{9)}$ i.e., heat treatment of the RSSC in vacuum and nitrogen atmosphere yielding, (1) removal of residual silicon, (2) nitrogen doping for the in-situ forming of $\beta-\mathrm{SiC}$, and (3) formation of a trace of $\mathrm{Si}_{3} \mathrm{~N}_{4}$ undetectable in XRD, is an efficient way to realize a material that can be used for $\mathrm{SiC}$ hot-surface igniters with the characteristics of fast heating speed and prevention of high temperature overshooting.

\section{Conclusion}

An M-shaped SiC gas igniter was fabricated by using a material prepared by reaction-sintering followed by nitrogen doping. The nitrogen-doped $\mathrm{SiC}$ gas igniter showed a reduced electrical resistivity at room temperature as compared to existing commercial SiC igniters. Also, a considerably lower NTC to PTC transition point, and smaller resistivity drop with joule heating (higher resistivity at high temperature), were demonstrated. It was deduced that the doped nitrogen reduces the electrical resistivity at room temperature, while, at high temperature, the doped nitrogen and the trace of $\mathrm{Si}_{3} \mathrm{~N}_{4}$ phase work as scattering centers against electron transfer, resulting in a lowered NTC-to-PTC transition point (below $650^{\circ} \mathrm{C}$ ). The nitrogen-doped $\mathrm{SiC}$ igniter with such characteristics demonstrated a faster rising temperature due to the lower room temperature resistivity. It also demonstrated the prevention of high temperature overshooting due to the characteristics of lower NTC to PTC transition point and smaller resistivity drop during joule heating. 


\section{Acknowledgments}

This work was supported by the R\&D Project of Gangneung Science Park Fosterage Program, funded by the Ministry of Education, Science and Technology (MEST) of Korea through the Gangneung Science Industry Foundation (GSIF). It was also partially supported by the Basic Science Research Program through the National Research Foundation of Korea (NRF), funded by the MEST (2010-0004150).

\section{REFERENCES}

1. K. Pelissier, T. Chartier, and J.M. Laurent, "Silicon Carbide Heating Elements," Ceram. Int., 24 371-77 (1998).

2. T. W. Choi and H.-L. Lee, "Oxidation Mechanism of SiC," J. Kor. Ceram. Soc., 18 [2] 79-82 (1981).

3. G. G. Trantina and R. L. Mehan, "High-Temperature TimeDependent Strength of an Si/SiC Composite," J. Am. Ceram. Soc., 60 177-78 (1977).

4. R. L. Mehan, "Effect of SiC Content and Orientation on the Properties of Si/SiC Ceramic Composite," J. Mat. Sci., 13 358-66 (1978).

5. W. B. Hilling, R. L. Mehan, C. R. Morelock, V. J. Decarlo, and W. Laskow, "Silicon/Silicon Carbide Composite," Am. Ceram. Bull., 54 1054-56 (1975).

6. K. L. Luthra, R. N. Singh, and M. K. Brun, "Toughened Silicomp Composites-Process and Preliminary Properties," Am. Ceram. Soc. Bull., 72 79-85 (1993).

7. W. B. Hilling, "Making Ceramic Composites by Melt Infiltration," Am. Ceram. Soc. Bull., 73 56-62 (1994).

8. I.-S. Han, J.-H. Yang, and H.-S. Jung, "Effect of alpha-Silicon Carbide Particle Size in Reaction Bonded Silicon Carbide,"
J. Kor. Ceram. Soc., 27 [4] 583-87 (1989).

9. Y.-S. Jeon, H. Shin, Y.-H. Lee, and S.-W. Kang, "Reduced Electrical Resistivity of Reaction-Sintered SiC by Nitrogen Doping," J. Mater. Res., 23 [4] 1020-25 (2008).

10. Y.-S. Jeon, H. Shin, J.-S. Park, and S.-W. Kang, "Optimizing Electrical and Mechanical Properties of Reaction-Sintered $\mathrm{SiC}$ by using Different-Sized SiC Particles in Preform," J. Kor. Ceram. Soc., 45 [8] 439-42 (2008).

11. O. Fumio, "Method of Producing Silicon Carbide Sintered Body for Heater," US Patent, 117722 (2007).

12. Z. Tian, N.R. Quick, and A. Kar, "Laser-Enhanced Diffusion of Nitrogen and Aluminum Dopants in Silicon Carbide," Acta Materialia, 54 4273-83 (2006).

13. R. Pampuch, J. Bialoskoreki, and E. Walasek, "Mechanism of Reactions in the $\mathrm{Si}_{1}+\mathrm{C}_{\mathrm{f}}$ System and the Self-Propagating High-Temperature Synthesis of Silicon Carbide," Ceram. Int., 13 63-8 (1987).

14. R. Pampuch, E. Walaseki, and J. Bialoskoreki, "Reaction Mechanism in Carbon-Liquid Silicon Systems at Elevated Temperatures," Ceram. Int., 12 99-106 (1986).

15. D. Hary and R.F. Davis, "Investigation of Grain-Boundary Segregation in Ceramic Oxides by Analytical Scanning Transmission Electron Microscopy," J. Am. Ceram. Soc., 63 542-46 (1980).

16. T. Marushima, N. Ueda, M. Takeichi, F. Ishii, and Y. Iguchi, "Nitrogen Solubility in Liquid Silicon," Mater. Trans., 35 821-26 (1994).

17. R.I. Scace and G.A. Slack, "Solubility of Carbon in Silicon and Germanium," J. Chem. Phys., 30 1551-55 (1959).

18. C.-B. Lim and T. Iseki, "Formation and Transportation of Intergranular and Nodular Fine-Grained $\beta-\mathrm{SiC}$ in ReactionSintered SiC," Adv. Ceram. Mater., 3 590-94 (1988). 